\title{
CORRECTION
}

View Article Online

View Journal I View Issue

\section{Correction: A practical approach to calculate the time evolutions of magnetic field effects on photochemical reactions in nano-structured materials}

Cite this: Phys. Chem. Chem. Phys., 2015, 17, 12366

Tomoaki Yago* and Masanobu Wakasa

DOI: $10.1039 / c 5 c p 90061 a$

Correction for 'A practical approach to calculate the time evolutions of magnetic field effects on photochemical reactions in nano-structured materials' by Tomoaki Yago et al., Phys. Chem. Chem.

www.rsc.org/pccp Phys., 2015, DOI: 10.1039/c5cp00595g.

Some of the parameter values in Table 1 of the article are incorrect. The corrected values can be found in the amended Table 1 below.

Table 1 Cage parameters used for the SLE analysis; viscosity $(\eta)$ in the cage, mutual diffusion coefficient $(D)$ for the radical pair in the cage, escape probability $\left(P_{\text {esc }}\right)$ at the interface, radius $(R)$ of the cage, recombination reaction rate $\left(k_{\text {rec }}\right)$ at the closest radical-radical distance, respectively

\begin{tabular}{|c|c|c|c|c|c|}
\hline \multirow[b]{2}{*}{ No. } & \multicolumn{5}{|c|}{ Cage parameters } \\
\hline & $\eta / \mathrm{cP}$ & $D / \mathrm{m}^{2} \mathrm{~s}^{-1}$ & $P_{\text {esc }}$ & $R / \mathrm{nm}$ & $k_{\mathrm{rec}} / \mathrm{s}^{-1}$ \\
\hline 1 & 30 & $3.6 \times 10^{-11}$ & $7.8 \times 10^{-4}$ & 1.7 & $1.0 \times 10^{10}$ \\
\hline 2 & 30 & $3.6 \times 10^{-11}$ & $3.8 \times 10^{-4}$ & 2.5 & $1.7 \times 10^{9}$ \\
\hline 3 & 10 & $1.1 \times 10^{-10}$ & $2.2 \times 10^{-4}$ & 1.7 & $1.0 \times 10^{10}$ \\
\hline
\end{tabular}

The Royal Society of Chemistry apologises for these errors and any consequent inconvenience to authors and readers. 